University of Nebraska - Lincoln

DigitalCommons@University of Nebraska - Lincoln

USDA National Wildlife Research Center - Staff Publications
U.S. Department of Agriculture: Animal and Plant Health Inspection Service

2018

\title{
Social conformity affects experimental measurement of boldness in male but not female monk parakeets (Myiopsitta monachus)
}

\author{
Kaan Kerman \\ University of Florida, kaan.kerman@edu.unito.it \\ Kathryn E. Sieving \\ University of Florida \\ Colette St. Mary \\ University of Florida \\ Michael L. Avery \\ USDA, Wildlife Services, NWRC
}

Follow this and additional works at: https://digitalcommons.unl.edu/icwdm_usdanwrc

Part of the Life Sciences Commons

Kerman, Kaan; Sieving, Kathryn E.; Mary, Colette St.; and Avery, Michael L., "Social conformity affects experimental measurement of boldness in male but not female monk parakeets (Myiopsitta monachus)" (2018). USDA National Wildlife Research Center - Staff Publications. 2218.

https://digitalcommons.unl.edu/icwdm_usdanwrc/2218

This Article is brought to you for free and open access by the U.S. Department of Agriculture: Animal and Plant Health Inspection Service at DigitalCommons@University of Nebraska - Lincoln. It has been accepted for inclusion in USDA National Wildlife Research Center - Staff Publications by an authorized administrator of DigitalCommons@University of Nebraska - Lincoln. 


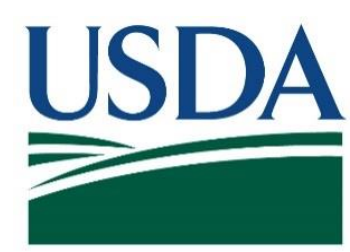

U.S. Department of Agriculture

U.S. Government Publication

Animal and Plant Health Inspection Service

Wildlife Services 


\title{
Social conformity affects experimental measurement of boldness in male but not female monk parakeets (Myiopsitta monachus)
}

\author{
Kaan Kerman $^{\mathrm{a}, *}$, Kathryn E. Sieving ${ }^{\mathrm{a}}$, Colette St. Mary ${ }^{\mathrm{b}}$ and \\ Michael L. Avery ${ }^{\mathrm{c}}$ \\ ${ }^{a}$ Department of Wildlife Ecology and Conservation, University of Florida, Gainesville, \\ FL 32611, USA \\ ${ }^{\mathrm{b}}$ Department of Biology, University of Florida, Gainesville, FL 32611, USA \\ ${ }^{c}$ USDA Wildlife Services, National Wildlife Research Center, Florida Field Station, \\ Gainesville, FL 32641, USA \\ *Corresponding author's current address: Department of Life Sciences and Systems \\ Biology, University of Turin, Turin, Italy, e-mail: kaan.kerman@edu.unito.it
}

Received 10 June 2018; initial decision 13 July 2018; revised 22 August 2018; accepted 20 September 2018; published online 2 October 2018

\begin{abstract}
The standard approach for characterizing boldness rarely considers the influence of social environment on the expression of boldness in group-living animals. We studied a wild-caught, captive population of monk parakeets (Myiopsitta monachus) to investigate the impact of conspecific presence on boldness - a personality trait in monk parakeets - in a controlled environment. We quantified seven boldness metrics across three types of behavioural assay: novel object, emergence, and predator exposure tests in the presence of a companion pair of flock mates. Because of the high degree of sociality in this species, we hypothesized that the presence of companion birds would facilitate the focal individuals' behavioural responses (i.e., increase the average boldness level). We found that behavioural response in a risky foraging context was inversely correlated between solitary and social condition in males, but not in females. Our results have implications for characterizing sex-specific differences of risk-taking behaviour in social animals.
\end{abstract}

\section{Keywords}

novel object test, emergence test, predation risk, latency to eat, neophobia, shyness, personality. 


\section{Introduction}

Boldness is apparently a universal personality trait evident throughout various animal taxa (Wilson et al., 1994; Carere \& Maestripieri, 2013), and is usually defined as consistent individual differences in propensity to face potential threats in the environment, such as those involved in information gathering, or access to resources (Reaney \& Backwell, 2007; Dammhahn $\&$ Almeling, 2012). In this framework, animals are usually exposed to riskrelated situations solitarily so that researchers can characterize individual variation by excluding extrinsic factors in the environment (Webster \& Ward, 2011). However, social animals are more likely to encounter potential risks in the presence of their fellow conspecifics. For instance, sociality in birds is a prevalent phenomenon. More than eight percent of avian species are cooperative breeders (Jetz \& Rubenstein, 2011), many more live in extended family groups (Brown \& Brown, 1981), and at least 21 percent of all avian taxa are known to participate in mixed species flocks either seasonally or year round (Gill \& Donsker, 2014; Zou et al., 2018). Thus, birds not only represent a suitable model system to examine the behavioural consequences of sociality on the bold-shy continuum, but such research is necessary to understand the ecological role of boldness expression in birds as a taxonomic group.

\subsection{Varied influences of social partners in avian boldness expression}

A complication in discerning this complexity is that the vast majority of boldness testing, especially in birds, occurs in experiments where subjects are tested solely in solitary conditions (Webster \& Ward, 2011). However, expanding interest in how boldness interacts with decision-making in birds underscores the reality that social environment is a central factor in the expression of boldness as a risk-taking strategy (Harel et al., 2016; Hua et al., 2016; Jolles et al., 2016). Presence or actions of group members can reduce the expression of risk-taking behaviour in an individual (e.g., social inhibition; raven, Corvus corax, Stowe et al., 2006; zebra finch, Taeniopygia guttata, Mainwaring et al., 2011; Indian mynah, Acridotheres tristis, Griffin et al., 2013). Conversely, group members' participation may also facilitate the expression of risk-prone phenotypes (e.g., kea, Nestor notabilis, Huber et al., 2001; great tit, Parus major, van Oers et al., 2005; barnacle goose, Branta leucopsis, Kurvers et al., 2012). Finally, individuals' risk-taking behaviour may conform to the behaviour of others in a social setting, such 
that risk-prone individuals become less so in the presence of a risk-averse individual, and vice versa (Gouldian finch, Erythrura gouldiae, King et al., 2015). In avian species, facilitative or inhibitory effects of sociality can be crucial for successful resolution of risky encounters such as avoiding predator encounters (Lazarus, 1979; Boland, 2003), locating and utilizing food resources (Soma \& Hasegawa, 2004; Jackson et al., 2008), and exploration of novel environments (Grigor et al., 1995; Sieving et al., 2004).

Sex also plays a key role in the expression of boldness towards risky stimuli (Schuett \& Dall, 2009; Schuett et al., 2010). For example, repeatability of boldness response can be dependent on the sex of the individual being tested; in some studies, male boldness was highly consistent (e.g., zebra finch, Schuett \& Dall, 2009) whereas in other tests females exhibited high consistency (e.g., jungle fowl, Gallus gallus, Favati et al., 2015). Sexes may also diverge in relative boldness as one sex becomes bolder than the other sex (zebra finch, Mainwaring et al., 2011; wandering albatross, Diomedea exulans, Patrick et al., 2013). More importantly, mate choice and reproductive success can be modulated by the boldness of the opposite sex (zebra finch, Schuett et al., 2011; great tit, David et al., 2015; African penguin, Spheniscus demersus, Traisnel \& Pichegru, 2018). In all of these cases, the social environment acts as a setting within which these sex-specific effects transpire. Although a few of these studies has touched upon the importance of sex on the expression of boldness traits across social context (Schuett \& Dall, 2009), we are yet to fully understand all the variegated ways that sex can influence risk-taking behaviour in animals with rich social lives.

\subsection{Study objectives}

To this end, we studied the expression of boldness in a highly gregarious parrot species, the monk parakeet (Myiopsitta monachus), with and without conspecific presence. The social complexity of this species, like other Psittaciformes (Sewall, 2015; Cussen, 2016), is characterized as extreme among major vertebrate taxa and heavily influences the species' life history (Hobson et al., 2012). The monk parakeet is a medium-sized parrot species native to South America, but also living in many introduced populations across the globe (Avery et al., 2012). Living in close-knit groups year-round, it exhibits communal roosting, foraging, and nesting behaviour (Collar, 1997, Pepperberg \& Shive, 2001). Communal nest sites are occupied by reproductive pairs or triads during the breeding season (Strubbe \& 
Matthysen, 2009), and are used for roosting outside of the breeding season (Eberhard, 1998). This facilitates the emergence of strong social bonds within groups, where individuals tend to form dominance hierarchies (Hobson et al., 2012), and help their kin in raising offspring (Homberger et al., 2008). Their social structure exhibits strong temporal stability in interaction patterns despite the fission-fusion dynamics in flocks (Hobson et al., 2014). The presence of high social cohesion and complex group dynamics make the monk parakeet an important model organism for examining the effects of social context and sex on the expression of avian personality traits. Furthermore, it broadens the number of species examined both with social and solitary personality tests, which will undoubtedly advance our understanding of how boldness is expressed in and out of groups for taxa across the continuum of social complexity.

The main goal of this study was to investigate the presence of sex-specific expression of boldness across different social situations. Given that the study species is intensely social - foraging, roosting and breeding in large flocks and likely keeping relationships with individuals over many years — we sought to evaluate whether boldness measures observed in standard solitary personality tests were consistent with results obtained in a group context. Using the same set of individual birds that were tested in a different year (reported in Kerman et al., 2016), we evaluated the effects of conspecific presence on the same standard risk-taking metrics across three behavioural assays for each sex: novel object, emergence in a new environment, and predator exposure tests. We conducted social assays of boldness where test subjects were accompanied by a pair of companions with mid-level boldness scores (with respect to the study flock), and compared boldness responses between the two social settings in this paper.

We assessed all three main types of social mechanisms: facilitation, inhibition, and conformity as well as the role of sex in boldness expression. To assess direct facilitative or inhibitory effects, we looked at the change in overall boldness levels of birds across social context (solitary vs. social). For conformity, we looked at the correlation of individual boldness scores between contexts (solitary vs. social). Presence of a negative correlation was accepted as an evidence for conformity since individuals shifted their risk-taking behaviour in response to their social setting, conforming to the boldness levels of their mid-level conspecifics (i.e., bold individuals becoming shyer; shy becoming bolder). Presence of a positive correlation 
between contexts was also considered an evidence for conformity only if the range of risk-taking response decreased considerably in the presence of conspecifics. If that was the case, individuals, though retaining their relative ranks, still conformed to the behavioural scores of their companion birds. Since male and female monk parakeets appear to respond similarly towards novel stimuli in a solitary condition (Kerman et al., 2016), we expected to see no sex-specific change in boldness scores in individuals retested in both solitary and social conditions.

\section{Material and methods}

\subsection{Study population and housing}

We studied a captive population of monk parakeets $(N=41 ; 21$ females and 16 males) at the USDA/APHIS Wildlife Research Centre, Florida Field Station, Gainesville, FL, USA. At the time of the study, the parakeets had been in captivity for 6 years. We held them in communal cages as mixedsex flocks with food and water, ad libitum. Since birds lived in pens of 2 to 6 individuals near all other flock members in the same facility since capture, and were transferred and mixed among communal cages intermittently over the years, we assumed the levels of familiarity among individuals were equivalent across our study population. All individuals survived the testing regime and continued to be housed at the facility after the completion of this study. Birds were not allowed to breed in captive conditions. For detailed descriptions of the methodological procedures implemented for trapping, transporting and housing birds, see Kerman et al. (2016).

\subsection{Experimental design}

We used a fixed order, repeated-measures design to compare the behavioural output of individuals previously tested in a solitary setting (results published in Kerman et al., 2016) in the presence of a pair of companion birds (this study). We conducted social assays opportunistically in 2014, approximately a year after solitary measures were collected in 2013. Since testing the entire flock in either social or solitary conditions takes more than 2 months, we chose this design to ensure that social and solitary tests occurred in the same seasonal (and hormonal) conditions, and to minimize the likelihood of habituation or testing fatigue. We applied three types of behavioural assays, as detailed below, that captured a total of seven boldness metrics: novel 
object, emergence, and predator exposure tests (Table 1). All observations were done by KK.

\subsection{Forming companion pairs}

We selected eight individuals (four females, four males) to be used only as companions during the assays; these individuals were not themselves tested in the social assays. Companion birds were selected because they expressed mid-level behavioural scores in solitary tests (Kerman et al., 2016). We housed companion birds in mixed-sex dyads across four cages, and placed them in their cages two weeks prior to the beginning of behavioural assays. We maintained the same male-female companion pairs throughout the study; three of these pairs were randomly assigned to birds tested in novel object tests, while the remaining pair was used as the sole companion pair for emergence and predator exposure tests. We decided not to switch companion pairs or form new ones between our trials out of the concern that frequent disruption of companion individuals could influence the behaviour of focal birds and confound trial results. For each assay, we housed companion pairs in their own cages adjacent to the focal birds being evaluated. We assume that 'companionship' in our study represented relatively neutral 'presence' of known social partners (flock mates) because we did not observe overt agonistic or courtship behaviour between companion individuals or focal and companion birds.

\subsection{Novel object test}

We conducted novel object tests in three small-sized cages that were visually but not acoustically separated from one another by opaque sheets $(1.8 \times$ $1.2 \times 1.2 \mathrm{~m}$; Figure 1). Each cage contained two brown terra cotta plant saucers to provide food and water. We placed four large perching branches of equivalent dimensions inside the experimental cages. Each focal bird's cage was adjacent to the cages of its assigned companion pair, enabling all three birds to maintain visual and aural but not physical contact during trials

We started each week by transferring three randomly selected test birds to their experimental cages, where they were acclimated to the testing aviary for four days prior to testing (days 1-4). Subjects were assigned to test cages in a randomized fashion. We tested birds on day five, then placed them back to their original cages on the same day. We implemented a two-day recovery period (days 6 and 7) before the next round of trials on a new set of birds the following week. 


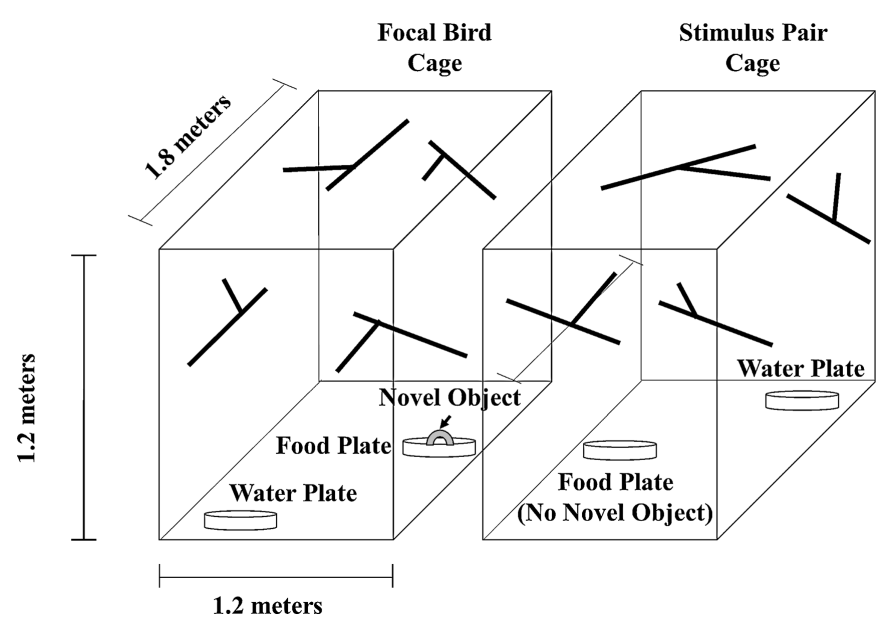

Figure 1. A diagram of the novel object arena. Thick lines represent branches and twigs inside the cage.

On days one through four of the novel object tests, we placed food saucers containing maintenance diet of seeds in the cages at $0830 \mathrm{~h}$ and removed them at $1630 \mathrm{~h}$ each day. Both focal and stimulus birds were subjected to the same protocol. On test day (day 5), we placed food plus novel objects within each food saucer, and presented them to focal birds at $0830 \mathrm{~h}$. Only focal individuals received a novel object inside the food saucer; social companions had only food inside the saucer. Novel objects varied from the ones used in the solitary assays published previously (see Kerman et al., 2016). We used a combination of a plastic bag clip and a rubber ring as novel stimulus. Once the food cups were placed inside, we started videotaping the focal individuals for 90 min by using Panasonic HCV100M cameras situated in front of the test cages. No human observer was present for the remainder of the test. We quantified four behavioural metrics, as detailed in Table 1. All trials were completed by noon.

\subsection{Emergence and predator exposure tests}

Emergence and predator exposure tests were conducted in a medium-sized aviary $(1.2 \times 1.8 \times 2.5 \mathrm{~m}$, Figure 2$)$. The aviary was located at a different section of the research facility than the one used in the previous study (see Kerman et al., 2016), and maintained the same dimension and design. We placed eight branches inside the aviary. One side of the aviary was 
Table 1.

List of behavioural measures used, and the experimental setting within which the measures were captured (adapted from Kerman et al., 2016).

Behavioural measure

Experimental setting

Latency to enter the novel environment and perch on a branch after the opening of the release cage door. Quantified as total number of seconds.

Latency to consume once the food saucer, with a novel object situated in the middle of the saucer, is placed in the test cage. Quantified as total number of seconds until the bird pecks at seeds for the first time.

Proportion of time spent feeding during the test period. Feeding activity involved handling and consuming while in close proximity to the food saucer. Quantified as total number of seconds spent feeding, divided by the total test period in seconds.

Foraging rate was quantified as the total number of pecks at the food source over the time spent foraging during the trials (seconds). Individuals bobbed their heads in a distinct pattern when pecking consecutively, facilitating the quantification process.

Total number of feeding approaches over the entire test period. Counting of feeding approaches started when the bird made its first successful feeding approach. Each feeding approach ended when birds flied to a branch or moving approximately $30 \mathrm{~cm}$ away from the food saucer.

Total number of vocalizations while exposed to a predator Emergence test

Novel object test

Novel object test during the test. Quantified number of distress calls when the predator is in the visual range.

Number of flights when exposed to a predator; quantifying each distinct flights and hops started when the bird left its perch and ended when bird landed on another perch.

Please see Kerman et al. (2016) for detailed information about the selection of behavioural assays and associated metrics.

completely covered with opaque material to hide the presence of human observers during behavioural trials. We mounted a release cage on the opaque wall with a rope attached to its door, enabling us to introduce focal birds inside the test arena at a distance. We transferred the social companions two weeks prior to the beginning of personality trials into a viewing compartment separated from the focal bird test arena by a thin mesh barrier. The viewing compartment had the same dimensions as the test arena. 

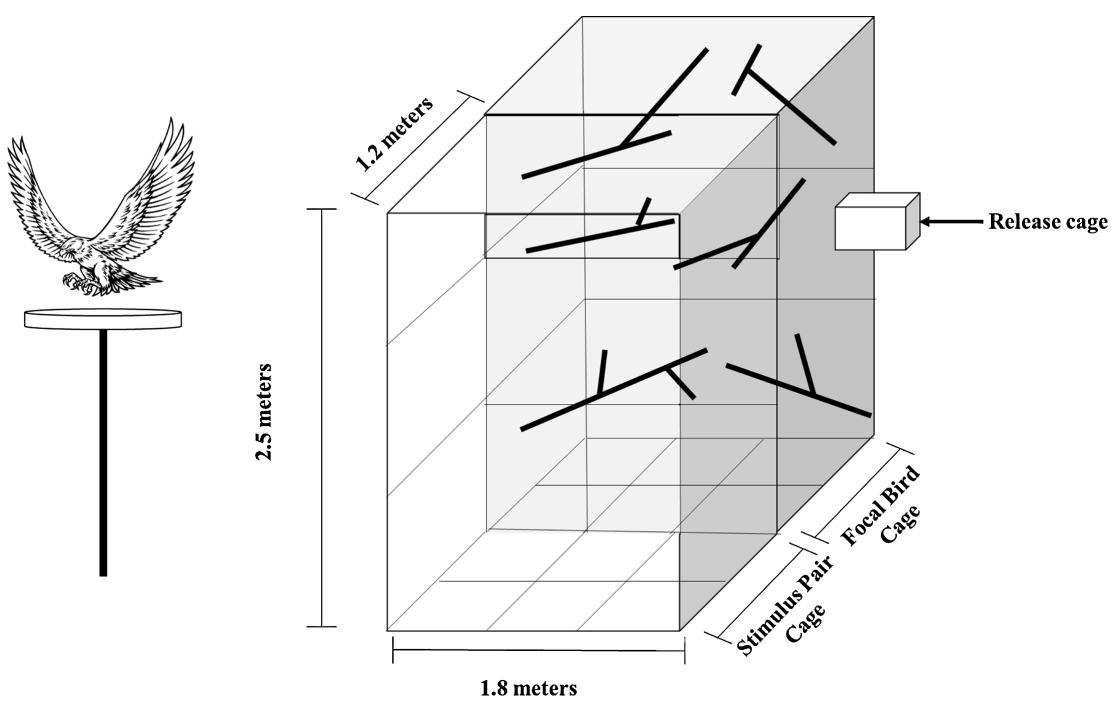

Figure 2. A diagram of the emergence and predator exposure arena. Thick lines represent branches and twigs inside the cage. The side coloured in dark grey depicts the opaque cover behind which the observer stands.

We placed a well-preserved sharp-shinned hawk (Accipiter striatus) specimen outside the aviary as a proxy for a real predator encounter, and hid it behind an opaque sheet until the beginning of the exposure period. Ecological information regarding avian predation activities on introduced monk parakeet populations in North America is extremely limited (Avery et al., 2012). Nevertheless, observations in their native habitats shows that some members of owl and hawk families could regularly be found occupying monk parakeet nests in South America, acting as nest predators (Martella \& Bucher, 1984), and observations on invasive monk parakeet populations in North America showed that they emit alarm calls when they have detected an aerial predator (South \& Pruett-Jones, 2000). Moreover, the sharp-shinned hawk is a relevant avian predator model as they are year-round residents in the native habitats of monk parakeets in South America, and they have overlapping distribution with introduced populations of monk parakeets in Florida (where our study birds were captured) except the summer months (White et al., 2018).

Tests began by placing a focal bird inside the release cage. We implemented a five min acclimatization period so that subjects were calm enough before the beginning of the trial. As soon as the cage door was open, we 
measured the latency of focal birds to enter the novel environment as the sole metric for the emergence test. Once focal birds entered the test arena, we waited for $20 \mathrm{~min}$ to allow focal birds to habituate to their surroundings. All individuals initiated preening well before the habituation period ended, which was considered a relaxed behaviour (Blumstein, 2003). At the end of the habituation period, we exposed the predator model by pulling a cord attached to the sheet in front of the predator model. We quantified the following behavioural output in the first minute that the predator was exposed: number of distress calls and number of flight attempts after exposed to predator models (Table 1). Distress calls were determined using the previous information published on monk parakeet vocalization (Martella \& Bucher, 1990). At the end of each trial, we replaced the sheet, hiding the predator model from view. All birds reacted immediately when the predator behind the plastic cover was exposed by emitting distress calls and initiating short bursts of flight. They resumed normal behaviour when the cover was replaced at the end of the observation period. Similar to novel object tests, we filmed behavioural responses through cameras stationed behind a small opening in the opaque barrier. Behavioural trials continued from $0830 \mathrm{~h}$ to $1130 \mathrm{~h}$, enabling us to test $2-3$ birds a day over 11 days.

\subsection{Statistical analysis}

We used R packages "multigroup" for principal component analysis, "stats" for correlation analysis, and "ggplot2" for graphical output (R Team, 2002; Wickham et al., 2013; Eslami et al., 2015).

\subsubsection{Identifying behavioural axes}

We relied on principal component analysis (PCA) to assess how multiple, commonly used risk-taking measures from different assays were related to one another. This approach has previously been used effectively to characterize personality variation in monk parakeet in social isolation (see Kerman et al., 2016). We implemented a multi-groups principal components analysis (mgPCA; Thorpe, 1988), a statistically more robust version of standard PCA where behavioural observations obtained from both solitary (which were published in Kerman et al., 2016) and social trials could be pooled and analysed together. Multi-groups PCA generates variance-covariance matrices by centring data within each treatment (solitary and social) while retaining individual identities (corresponding to the same individuals; Krzanowski, 1979; 
Abdi et al., 2013; Huang et al., 2016). Using mgPCA, we could obtain component axes comprised of combined data from both contexts (in order to identify distinct latent behavioural traits) and, in turn, we could then parse the data into subsets according to the treatment group to conduct inferential analysis. In order to satisfy the assumptions of normality for PCA, we applied a log-normal transformation of latency and rate measures (Girard et al., 2004; Krause \& Naguib, 2011), square-root transformation of count measures (Moretz et al., 2007), and arcsine square-root transformation of proportional measures (David et al., 2011); normality was confirmed with normal probability plots. Principal components (PCs) with Eigenvalues $<1.0$ were excluded from further interpretation (Kaiser, 1960). In assessing the relative importance of component loadings on each PC, we used a cut-off value of $\geqslant 0.4$ (Stevens, 1992; van den Brink et al., 2012).

According to our analysis, only PC1 and PC2 (i.e., boldness during foraging and predator encounter, respectively) retained comparable loading values across solitary and social conditions (i.e., behavioural measures that had high loading values were similar across contexts), thus representing distinct latent behavioural traits (Table 2). Therefore, we focused our inferential analyses on those two components.

\subsubsection{Evaluating social facilitation and inhibition}

We looked at whether the presence of companion birds increased (i.e., facilitated) or decreased (i.e., inhibited) the overall expression of risk-taking behaviour by comparing boldness scores obtained in social isolation to scores obtained in conspecific presence (for all individuals, then for each sex separately). Since component scores were calculated through linear combinations of centred behavioural measures, any analysis of variance could fail to detect the overall direction of change in risk taking behaviour. We therefore used Wilcoxon signed-rank test - a non-parametric test suitable for repeated measurement on the same set of individuals - on each metric that had loadings equal or larger than 0.4 in the components. Finally, we adjusted the significance level using the Bonferroni correction $(\alpha=0.003)$ to avoid the inflation of Type-I error.

\subsubsection{Evaluating social conformity}

We looked at whether bold individuals became shyer, and vice versa when behavioural assays were implemented with companion birds. We obtained component scores for PC1 and PC2, and compared each component's scores 
between solitary and social conditions using Spearman's rank-order correlation to detect rank changes (Wilson \& Godin, 2010; Gyuris et al., 2012). We ran repeated correlation analyses by first pooling individuals from both sexes, and then with each sex separately.

\section{Results}

In all of our behavioural assays (novel object, emergence and predator exposure tests), monk parakeets responded to risky stimuli within the observation period (Table 2). In the social treatment, sexes did not differ significantly from one another in any of our seven metrics used in the behavioural assays (see Appendix).

\subsection{Social facilitation/inhibition}

Considering the hypotheses that the presence of companions would either facilitate or inhibit boldness behaviour, we did not find a unidirectional change associated with social environment in any of the behavioural measures loaded on PC1 and PC2 (Table 3).

\subsection{Conditional change in boldness}

Considering the hypothesis that individuals should react conditionally to conspecifics' boldness phenotype (i.e., conformity), we did not observe a significant correlation in boldness scores across social context for either behavioural dimension when both sexes were pooled: boldness in a foraging context (i.e., PC1) and boldness in a predation context (i.e., PC2, Table 4). Males, but not females, showed an inverse correlation between social and solitary treatments for boldness response captured in a risky foraging test $\left(R_{S}=-0.67 ; p=0.02\right.$; Figure 3$)$, but neither sex showed significant correlation in the predation test (Table 4).

\section{Discussion}

\subsection{Males but not females exhibited social conformity}

We found that male monk parakeets that are risk-aversive in a foraging context adopted a more risk prone phenotype when conspecifics were nearby, and vice versa. Thus, males appear to conform to social partners in their presence. Females, on the other hand, failed to exhibit a similar type of conformity in their boldness response. Interestingly, this effect is despite the fact 


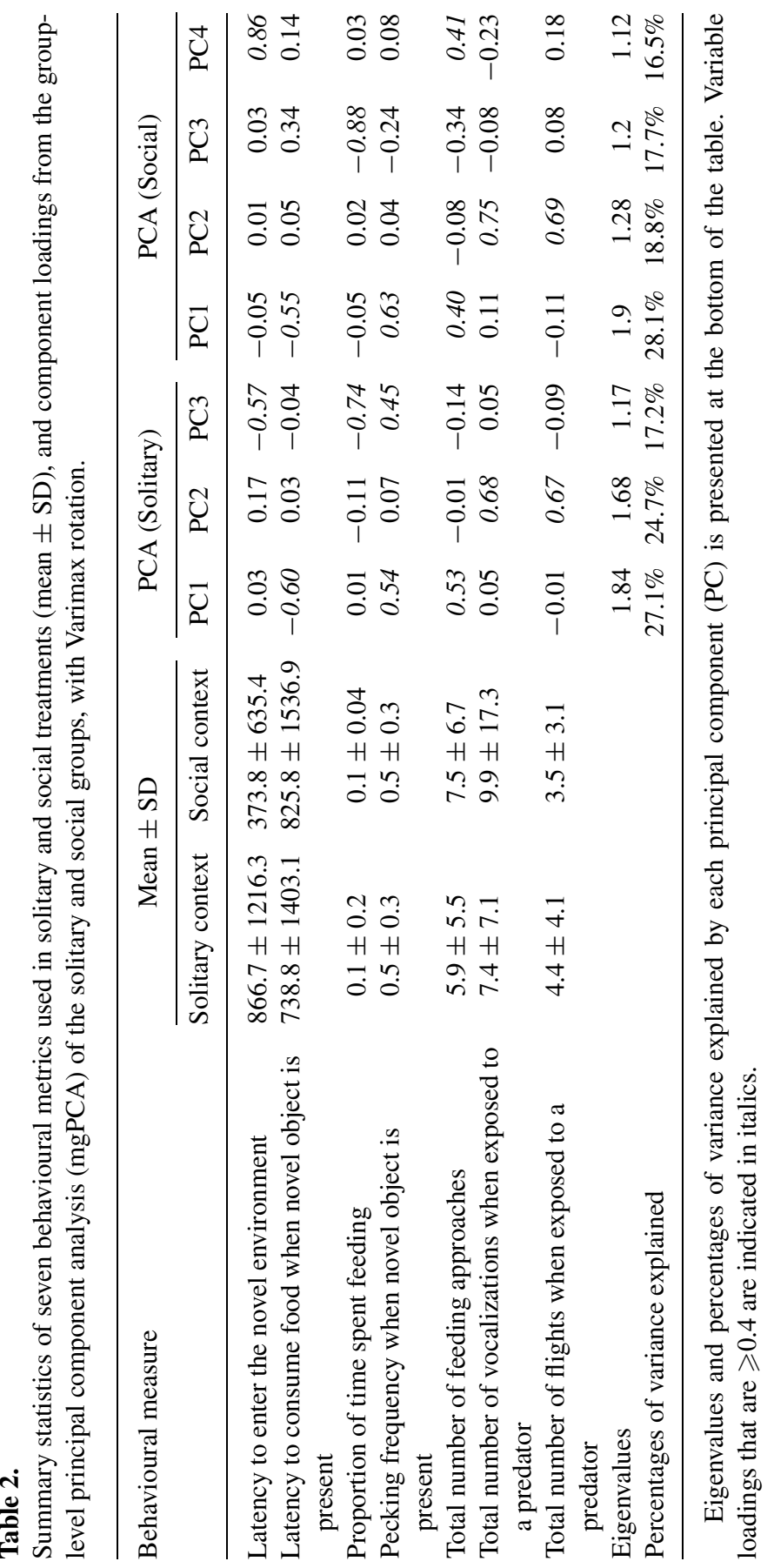




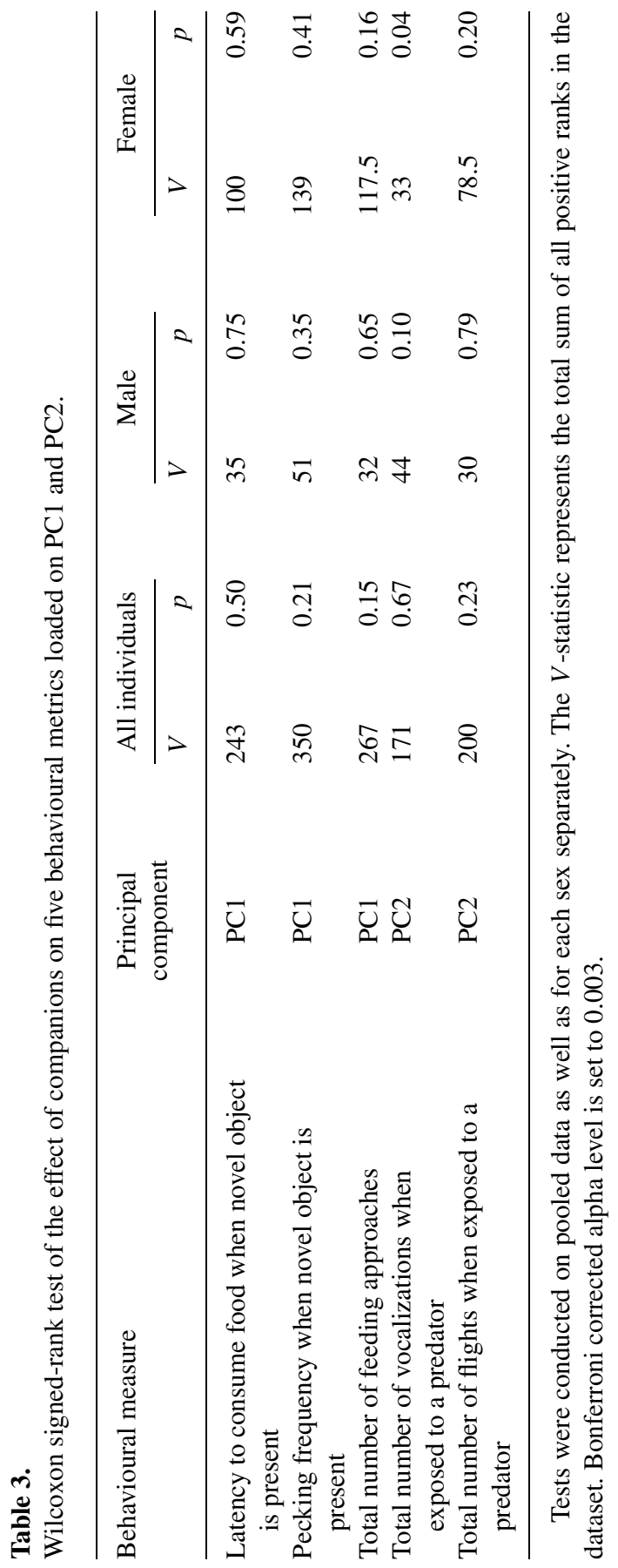


Table 4.

Spearman rank-order correlation analysis on PC1 and PC2 scores for all individuals, as well as for each sex.

\begin{tabular}{lrcrcc}
\hline & \multicolumn{2}{c}{ PC1 } & & \multicolumn{2}{c}{ PC2 } \\
\cline { 2 - 3 } \cline { 5 - 6 } & \multicolumn{1}{c}{$R_{S}$} & $P$ & & $R_{S}$ & $P$ \\
\hline All individuals & -0.12 & 0.49 & & -0.10 & 0.65 \\
Males & -0.67 & 0.02 & & -0.01 & 0.99 \\
Females & 0.19 & 0.42 & & -0.14 & 0.55 \\
\hline
\end{tabular}

that males and females exhibited similar levels of response when exposed to a novel object in the context of a foraging task.

Conformity reflects individual preferences that are modified after the interaction with a group member, even if the adopted behaviour is the lesspreferred one (Galef \& Whiskin, 2008). Initially described in humans and non-human primates (Cialdini \& Goldstein, 2004; Whiten et al., 2005; Dindo et al., 2009; van de Waal et al., 2013), conditional change in behaviour in response to the actions of conspecific individuals has been documented in other vertebrate groups such as rodents (Galef \& Whiskin, 2008; Jolles et al., 2011), birds (Aplin et al., 2015; King et al., 2015), and fish (Day et al., 2001; Webster \& Laland, 2012). One of the demonstrated selective advantages of conforming to group behaviour is acquiring behavioural norms that

A

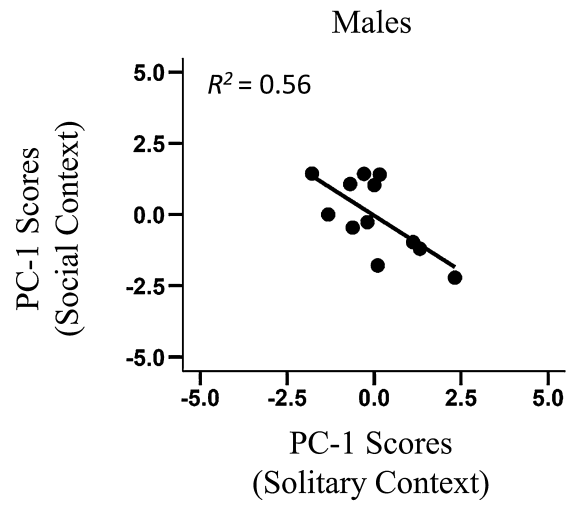

B

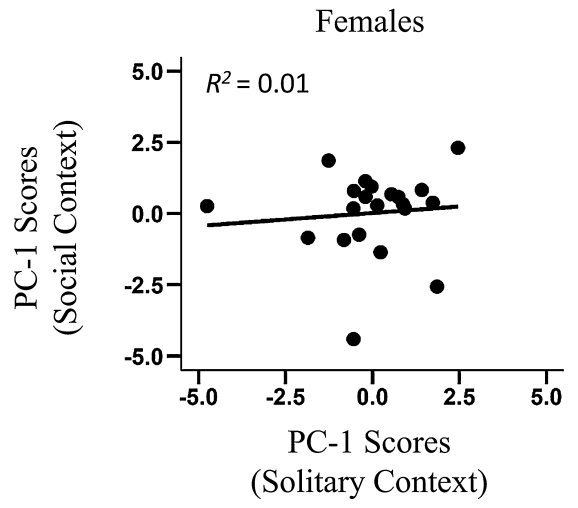

Figure 3. The linear relationship of PC1 scores between solitary and social contexts in (A) males and (B) females. The regression lines and the amount of variation explained by each regression model are presented in the figures. 
help them utilize local food resources, which newly immigrated individuals rely on after their dispersal into a new social group (Vale et al., 2017). For species that show sex-specific natal dispersal patterns, we would expect individuals of the emigrating sex to have a higher tendency towards conformity in response to risk-related events, so that they can better adapt to their novel environment and maximize their fitness through observation of the local preferences in their new social groups (van de Waal et al., 2013). For example, naïve male vervet monkeys (Chlorocebus pygerythrus) that immigrated to a novel troop quickly adopt the alternative food option that are preferred by existing group members (van de Waal et al., 2013), while females — which is the philopatric sex - do not exhibit this similar behavioural response as they do not change groups and act instead as the main hub of social attention and directed social learning due to their long experience in the environment (van de Waal et al., 2010; Renevey et al., 2013). It is an interesting possibility that a similar selection mechanism could be involved in the male-biased conformity in monk parakeets.

Monk parakeets are known to exhibit philopatry as they tend to use the same communal nest site over multiple years (Collar, 1997, Pepperberg \& Shive, 2001). They disperse from their natal site only relatively short distances (Martin \& Bucher, 1993; Bucher \& Aramburú, 2014), though their dispersal range is larger in non-native habitats potentially due to humanassisted introduction events (da Silva et al., 2010; Edelaar et al., 2015). Unfortunately, since monk parakeets do not show marked sexual dimorphism, there is no information from these studies about sex-specific patterns in dispersal events. While female-biased dispersal is considered the norm in birds, male biased dispersal does occur (Clarke et al., 1997) and has been confirmed in Psittaciformes (Caparroz et al., 2009). We therefore propose male-biased dispersal in monk parakeets should be considered in a future study.

\subsection{Potential confounding factors}

While we are quite confident in the validity of our findings, documentation of animal behavioural syndromes is complex and very popular now. In order that we may provide insights that can strengthen future study designs, we undertake a careful examination of our procedures. One potential factor that could influence the observed boldness response in this study is the size of the social unit used during assays. How individuals respond to risky conditions in different group sizes depends on the taxonomic and ecological context within which the behaviour arises. In fish, for example, larger 
groups of guppies (Poecilia reticulata) tended to exhibit greater conformity in entering a novel environment and foraging on a novel food item (Day et al., 2001). In contrast, smaller groups of perch (Perca fluviatilis) were more likely to conform to the overall risk-taking behaviour in emergence and predator exposure tests (Hellström et al., 2011). Also in birds, Kurvers et al. (2011) found that boldness affected decision making in barnacle geese when tests were conducted in pairs but not in larger groups. Although some evidence suggests that multiple monk parakeet pairs readily join others to form larger groups during food acquisition (e.g., fission-fusion dynamics, Hobson et al., 2014), our social setting (3 birds) characterizes a typical monk parakeet social sub-unit. Therefore, while we stress that the numerical definition of 'social condition' for any species in a study like ours should be made with care, we have no reason to believe that our social group construct was inadequate to detect the influence of social context on personality variation.

The role of a physical barrier between companion and focal bird cages, where some species were tested adjacent to a stimulus bird cage (e.g., great tit, van Oers et al., 2005), while others tested within a social group (e.g., Gouldian finch, King et al., 2015) should be fully investigated for an accurate representation of boldness in a given species (Kerman et al., 2018, in press). For example, housing in the same compartment can trigger agonistic interactions at the food cup, where dominant individuals displace subordinate birds, ultimately confounding their boldness response. In some cases, dominance rank successfully predicts the positioning on a bold-shy continuum in a foraging task (Dingemanse \& de Goede, 2004; Dahlbom et al., 2011; David et al., 2011), which gives the researchers enough confidence to discard it as a confounding effect. However, this association between boldness and dominance status is not universally true (Fox et al., 2009; Kurvers et al., 2009), and we did not know in advance if dominance in monk parakeets is related to their boldness scores or sex-specific responses during risky foraging. Under this uncertainty, testing focal birds in a separate compartment from companion pairs was the most rational approach, as even a partial cage division introduced recently can significantly reduce aggression and hierarchy-related anxiety in captive animals (Tallent et al., 2018). Further, monk parakeets housed in different cages lived in visual and aural contact with all other population members (small cages grouped together within a protected open-air aviary); thus individuals were already accustomed to this 
sort of physical arrangement. We therefore think that the effect of dominance related aggression is likely to be extremely limited or absent in our study.

Finally, we would like to consider two potential non-random influences on our ability to detect a true treatment response: (1) carryover effects (influences of solitary test protocols on the follow-up social test responses); and (2) chronic impacts of an extended period in captive conditions. A yearlong interval occurred between solitary and social assays. On the one hand, this long period likely eliminated carryover effects of the solitary trials into the social trials. However, this lengthy period could increase the potential for systemic shifts in extrinsic and intrinsic factors (e.g., stress, illness, environmental or caging changes; van Horik et al., 2017) affecting individual responses flock-wide. Through memory and experiences accumulated during long-term captivity consistent divergent alterations in behavioural response of individuals or sexes could have occurred (LaDage et al., 2009; Dingemanse et al., 2012). But while we acknowledge these possibilities as serious considerations in future research designs, especially in newly formed captive flocks, we do not think they were important in our study. The environment of our birds had been very stable over their 6 years of captivity prior to the solitary measures. The birds' daily and weekly maintenance regimen continued under the exact same animal care protocol across the entire time-period encompassing the solitary and social tests, with no systematic alterations in caging, feeding or health care. We still worried about other lesser unknown effects (e.g., undetected predator threats, unmeasured climatic shifts, etc.), and considered using a stronger design (involving splitting the flock in two halves with social and solitary treatment applied to each half in different orders) to control for unknown temporal shifts. But we also had constraints on space and cage availability in undisturbed areas of the site, and a critical requirement for seasonal consistency (see Methods) such that the latter design could not have been implemented without introducing other, more serious, complications. All in all, we are confident that we chose the strongest and least biased design for our study, given local constraints; that major unknown biases were adequately controlled by the strict flock management regimen. We provide these comments to encourage attention to achieving the strongest designs when testing behavioural outputs in higher vertebrates in general, and carefully considering both hierarchical formation and size of social groups in further tests of sex influences on risk-taking behaviour in this and other vertebrates. 


\section{Conclusion}

The nature of social effects on personality expression are complex and therefore is not simple to characterize. Even though animals exhibit variation in personality, individual behavioural patterns are mediated by a variety of social interactions in group-living organisms (Farine et al., 2015; Vander Wal et al., 2015). Thus, ignoring sociality in quantifying individuals' risk-taking behaviours might inaccurately reflect the ecological and evolutionary implications of boldness in natural populations (Webster \& Ward, 2011). Here, we provide support for the importance of sociality in the investigation of animal personality traits and its relation to sex-specific foraging behaviour in groups (Toscano et al., 2016). Our study contributes to the small body of literature that documents the role of social context on personality traits and that either sex might be more responsive to social cues in a risk-taking context than the other. Our use of parallel social and solitary testing contexts is applicable in most taxa and across the spectrum of different personality axes (boldness, activity, aggression, etc.) and may help in achieving a general framework of social context effects on personality expression.

Many parrot species, including the monk parakeet, are either intruded upon by development in their native ranges or released into novel environments through human intervention (Russello, 2008; Strubbe \& Matthysen, 2009; Peck et al., 2014; Lopes et al., 2017). In such species, coping with novel challenges such as food-finding, which is often dependent on more extreme risk taking behaviours (Martin \& Fitzgerald, 2005; Short \& Petren, 2008; Lapiedra et al., 2017), can be strongly tied to personality expression in a social unit (Aplin et al., 2014). Therefore, across applied or theoretical undertakings where behavioural typing may be a useful tool, tests in a social group may be better suited, and should certainly be included, in evaluating personality trait influences on population parameters of social species (Evans et al., 2010; Mainwaring et al., 2011).

\section{Acknowledgements}

We would like to extend our gratitude to our colleagues in the laboratory of Dr. Kathryn E. Sieving for their constructive comments during the conception of this study. We appreciate the logistic support provided by the USDA staff members Kandy Keacher, Eddie Bruce and Eric Tillman. This study 
was approved by United States Department of Agriculture, and the University of Florida's Institutional and Animal Use Care Committee. Maintenance of captive monk parakeets was generously provided by the staff at USDA APHIS Florida Field Station in Gainesville, FL, USA.

\section{References}

Abdi, H., Williams, L.J. \& Valentin, D. (2013). Multiple factor analysis: principal component analysis for multitable and multiblock data sets. - Wiley Interdisciplinary Reviews: Computational Statistics 5: 149-179.

Aplin, L.M., Farine, D.R., Mann, R.P. \& Sheldon, B.C. (2014). Individual-level personality influences social foraging and collective behaviour in wild birds. — Proc. Roy. Soc. Lond. B: Biol. Sci. 281: 20141016.

Aplin, L.M., Farine, D.R., Morand-Ferron, J., Cockburn, A., Thornton, A. \& Sheldon, B.C. (2015). Experimentally induced innovations lead to persistent culture via conformity in wild birds. - Nature 518: 538.

Avery, M., Tillman, E., Keacher, K., Arnett, J. \& Lundy, K. (2012). Biology of invasive monk parakeets in South Florida. - Wilson J. Ornithol. 124: 581-588.

Blumstein, D.T. (2003). Flight-initiation distance in birds is dependent on intruder starting distance. - J. Wildl. Manage. 67: 852-857.

Boland, C.R. (2003). An experimental test of predator detection rates using groups of freeliving emus. - Ethology 109: 209-222.

Brown, J.L. \& Brown, E.R. (1981). Extended family system in a communal bird. - Science 211: 959-960.

Bucher, E.H. \& Aramburú, R.M. (2014). Land-use changes and monk parakeet expansion in the Pampas grasslands of Argentina. — J. Biogeogr. 41: 1160-1170.

Caparroz, R., Miyaki, C.Y. \& Baker, A.J. (2009). Contrasting phylogeographic patterns in mitochondrial DNA and microsatellites: evidence of female philopatry and male-biased gene flow among regional populations of the blue-and-yellow macaw (Psittaciformes: Ara ararauna) in Brazil. - Auk 126: 359-370.

Carere, C. \& Maestripieri, D. (2013). Animal personalities: behavior, physiology, and evolution. - Chicago, IL.

Cialdini, R.B. \& Goldstein, N.J. (2004). Social influence: compliance and conformity. Annu. Rev. Psychol. 55: 591-621.

Clarke, A.L., Saether, B.E. \& Roskaft, E. (1997). Sex biases in avian dispersal: a reappraisal. - Oikos 79: 429-438.

Collar, N.J. (1997). Family Psittacidae (parrots). — In: Handbook of the birds of the world 4: family Psittacidae (parrots) (del Hoyo, J., Elliott, A. \& Sargatal, J., eds). Lynx Edicions, Barcelona, p. 280-477.

Cussen, V.A. (2016). Psittacine cognition: individual differences and sources of variation. Behav. Process. 134: 103-109. 
Da Silva, A.G., Eberhard, J.R., Wright, T.F., Avery, M.L. \& Russello, M.A. (2010). Genetic evidence for high propagule pressure and long-distance dispersal in monk parakeet (Myiopsitta monachus) invasive populations. — Mol. Ecol. 19: 3336-3350.

Dahlbom, S.J., Lagman, D., Lundstedt-Enkel, K., Sundström, L.F. \& Winberg, S. (2011). Boldness predicts social status in zebrafish (Danio rerio). — PLoS One 6: e23565.

Dammhahn, M. \& Almeling, L. (2012). Is risk taking during foraging a personality trait? A field test for cross-context consistency in boldness. - Anim. Behav. 84: 1131-1139.

David, M., Cezilly, F. \& Giraldeau, L.A. (2011). Personality affects zebra finch feeding success in a producer-scrounger game. - Anim. Behav. 82: 61-67.

David, M., Pinxten, R., Martens, T. \& Eens, M. (2015). Exploration behavior and parental effort in wild great tits: partners matter. — Behav. Ecol. Sociobiol. 69: 1085-1095.

Day, R.L., MacDonald, T., Brown, C., Laland, K.N. \& Reader, S.M. (2001). Interactions between shoal size and conformity in guppy social foraging. - Anim. Behav. 62: 917925.

Dindo, M., Whiten, A. \& de Waal, F.B. (2009). In-group conformity sustains different foraging traditions in capuchin monkeys (Cebus apella). — PLoS One. 4: e7858.

Dingemanse, N.J. \& de Goede, P. (2004). The relation between dominance and exploratory behavior is context-dependent in wild great tits. - Behav. Ecol. 5: 1023-1030.

Dingemanse, N.J., Bouwman, K.M., Van De Pol, M., van Overveld, T., Patrick, S.C., Matthysen, E. \& Quinn, J.L. (2012). Variation in personality and behavioural plasticity across four populations of the great tit Parus major. - J. Anim. Ecol. 81: 116-126.

Eberhard, J.R. (1998). Breeding biology of the monk parakeet. — Wilson Bull. 110: 463-473.

Edelaar, P., Roques, S., Hobson, E.A., Gonçalves da Silva, A., Avery, M.L., Russello, M.A., Senar, J.C., Wright, T.F., Carette, M. \& Tella, J.L. (2015). Shared genetic diversity across the global invasive range of the monk parakeet suggests a common restricted geographic origin and the possibility of convergent selection. - Mol. Ecol. 24: 2164-2176.

Eslami, A., El Mostafa, Q.S.B., Sanchez, G., Bougeard, S. \& Eslami, M.A. (2015). Package 'multigroup'. - CRAN, Comprehensive R Archive Network for the R programming language.

Evans, J., Boudreau, K. \& Hyman, J. (2010). Behavioural syndromes in urban and rural populations of song sparrows. - Ethology 116: 588-595.

Farine, D.R., Montiglio, P.O. \& Spiegel, O. (2015). From individuals to groups and back: the evolutionary implications of group phenotypic composition. - Trends. Ecol. Evol. 30: 609-621.

Favati, A., Zidar, J., Thorpe, H., Jensen, P. \& Løvlie, H. (2015). The ontogeny of personality traits in the red junglefowl, Gallus gallus. — Behav. Ecol. 27: 484-493.

Fox, R.A., Ladage, L.D., Roth II, T.C. \& Pravosudov, V.V. (2009). Behavioural profile predicts dominance status in mountain chickadees, Poecile gambeli. - Anim. Behav. 77: 1441-1448.

Galef, B.G. \& Whiskin, E.E. (2008). 'Conformity' in Norway rats? - Anim. Behav. 75: 2035-2039.

Gill, F.B. \& Donsker, D. (2014). IOC World Bird List (v 4.3). Available online at http://www. worldbirdnames.org. 
Griffin, A.S., Lermite, F., Perea, M. \& Guez, D. (2013). To innovate or not: contrasting effects of social groupings on safe and risky foraging in Indian mynahs. - Anim. Behav. 86: 1291-1300.

Grigor, P.N., Hughes, B.O. \& Appleby, M.C. (1995). Social inhibition of movement in domestic hens. - Anim. Behav. 49: 1381-1388.

Gyuris, E., Fero, O. \& Barta, Z. (2012). Personality traits across ontogeny in firebugs, Pyrrhocoris apterus. - Anim. Behav. 84: 103-109.

Harel, R., Duriez, O., Spiegel, O., Fluhr, J., Horvitz, N., Getz, W.M., Bouten, W., Sarrazin, F., Hatzofe, O. \& Nathan, R. (2016). Decision-making by a soaring bird: time, energy and risk considerations at different spatio-temporal scales. — Philos. Trans. Roy. Soc. B: Biol. Sci. 371: 20150397.

Hellström, G., Heynen, M., Oosten, J., Borcherding, J. \& Magnhagen, C. (2011). The effect of group size on risk taking and social conformity in Eurasian perch. - Ecol. Freshw. Fish. 20: 499-502.

Hobson, E.A., Avery, M.L. \& Wright, T.F. (2012). An analytical framework for quantifying and testing patterns of temporal dynamics in social networks. - Anim. Behav. 85: 83-96.

Hobson, E.A., Avery, M.L. \& Wright, T.F. (2014). The socioecology of monk parakeets: insights into parrot social complexity. - Auk 131: 756-775.

Homberger, D.G., Enkerlin-Hoeflich, E.C., Snyder, N.F., Wiley, J.W., Munn, C.A., Graham, J., Wright, T.F., Dooling, R.J., Korbel, R., Seibert, L.M. \& Matson, K.D. (2008). Manual of parrot behavior. - Blackwell, Oxford.

Hua, F., Yong, D.L., Janra, M.N., Fitri, L.M., Prawiradilaga, D. \& Sieving, K.E. (2016). Functional traits determine heterospecific use of risk-related social information in forest birds of tropical south-east Asia. — Ecol. Evol. 6: 8485-8494.

Huang, P., Kerman, K., Sieving, K.E. \& St Mary, C.M.S. (2016). Evaluating the novelenvironment test for measurement of exploration by bird species. — J. Ethol. 4: 45-51.

Huber, L., Rechberger, S. \& Taborsky, M. (2001). Social learning affects object exploration and manipulation in keas, Nestor notabilis. - Anim. Behav. 62: 945-954.

Jackson, A.L., Ruxton, G.D. \& Houston, D.C. (2008). The effect of social facilitation on foraging success in vultures: a modelling study. — Biol. Lett. 4: 311-313.

Jetz, W. \& Rubenstein, D.R. (2011). Environmental uncertainty and the global biogeography of cooperative breeding in birds. - Curr. Biol. 21: 72-78.

Jolles, J.W., de Visser, L. \& van den Bos, R. (2011). Male Wistar rats show individual differences in an animal model of conformity. - Anim. Cogn. 14: 769.

Jolles, J.W., Benjamin, A.T. \& Manica, A. (2016). Recent social conditions affect boldness repeatability in individual sticklebacks. — Anim. Behav. 112: 139-145.

Kaiser, H.F. (1960). The application of electronic computers to factor analysis. - Educ. Psychol. Meas. 20: 141-151.

Kerman, K., Miller, L. \& Sewall, K. (2018). The effect of social context on measures of boldness: Zebra finches (Taeniopygia guttata) are bolder when housed individually. Behav. Process. 157: 18-23. 
Kerman, K., Sieving, K.E., St Mary, C. \& Avery, M.L. (2016). Evaluation of boldness assays and associated behavioral measures in a social parrot, monk parakeet (Myiopsitta monachus). - Behaviour 153: 1817-1838.

King, A.J., Williams, L.J. \& Mettke-Hofmann, C. (2015). The effects of social conformity on Gouldian finch personality. - Anim. Behav. 99: 25-31.

Krause, E.T. \& Naguib, M. (2011). Compensatory growth affects exploratory behaviour in zebra finches, Taeniopygia guttata. - Anim. Behav. 81: 1295-1300.

Krzanowski, W.J. (1979). Between-groups comparison of principal components. - J. Am. Stat. Ass. 74: 703-707.

Kurvers, R.H.J.M., Eijkelenkamp, B., van Oers, K., van Lith, B., van Wieren, S.E., Ydenberg, R.C. \& Prins, H.H.T. (2009). Personality differences explain leadership in barnacle geese. - Anim. Behav. 78: 447-453.

Kurvers, R.H.J.M., Adamczyk, V.M.A.P., van Wieren, S.E. \& Prins, H.H.T. (2011). The effect of boldness on decision-making in barnacle geese is group-size-dependent. — Proc. Roy. Soc. Lond. B: Biol. Sci. 278: 2018-2024.

Kurvers, R.H.J.M., Nolet, B.A., Prins, H.H.T., Ydenberg, R.C. \& van Oers, K. (2012). Boldness affects foraging decisions in barnacle geese: an experimental approach. - Behav. Ecol. 23: 1155-1161.

LaDage, L.D., Roth, I.I., Timothy, C., Fox, R.A. \& Pravosudov, V.V. (2009). Effects of captivity and memory-based experiences on the hippocampus in mountain chickadees. Behav. Neurosci. 123: 284.

Lapiedra, O., Chejanovski, Z. \& Kolbe, J.J. (2017). Urbanization and biological invasion shape animal personalities. - Global Change Biol. 23: 592-603.

Lazarus, J. (1979). Flock size and behaviour in captive red-billed weaverbirds (Quelea quelea): implications for social facilitation and the functions of flocking. - Behaviour 71: 127-144.

Lopes, A.R.S., Rocha, M.S., Junior, M.G.J., Mesquita, W.U., Silva, G.G.G.R., Vilela, D.A.R. \& Azevedo, C.S. (2017). The influence of anti-predator training, personality and sex in the behavior, dispersion and survival rates of translocated captive-raised parrots. - Glob. Ecol. Conserv. 11: 146-157.

Mainwaring, M.C., Beal, J.L. \& Hartley, I.R. (2011). Zebra finches are bolder in an asocial, rather than social, context. - Behav. Processes. 87: 171-175.

Martella, M.B. \& Bucher, E.H. (1984). Nesting of the spot-winged falconet in monk parakeet's nests. - Auk 101: 614-615.

Martella, M.B. \& Bucher, E.H. (1990). Vocalizations of the monk parakeet. - Bird. Behav. 8: $101-110$.

Martin, L.B. \& Fitzgerald, L. (2005). A taste for novelty in invading house sparrows, Passer domesticus. - Behav. Ecol. 8: 702-707.

Martín, L.F. \& Bucher, E.H. (1993). Natal dispersal and first breeding age in monk parakeets. - Auk 110: 930-933.

Moretz, J.A., Martins, E.P. \& Robinson, B.D. (2007). Behavioral syndromes and the evolution of correlated behavior in zebrafish. - Behav. Ecol. 18: 556-562. 
Patrick, S.C., Charmantier, A. \& Weimerskirch, H. (2013). Differences in boldness are repeatable and heritable in a long-lived marine predator. - Ecol. Evol. 3: 4291-4299.

Peck, H.L., Pringle, H.E., Marshall, H.H., Owens, I.P.F. \& Lord, A.M. (2014). Experimental evidence of impacts of an invasive parakeet on foraging behavior of native birds. - Behav. Ecol. 25: 582-590.

Pepperberg, I. \& Shive, H. (2001). Simultaneous development of vocal and physical object combinations by a grey parrot (Psittacus erithacus): bottle caps, lids, and labels. J. Comp. Psychol. 115: 376-384.

R Team (2002). The R stats package. - R Foundation for Statistical Computing, Vienna, available online at http://www.R-project.org.

Reaney, L.T. \& Backwell, P.R.Y. (2007). Risk-taking behavior predicts aggression and mating success in a fiddler crab. - Behav. Ecol. 18: 521-525.

Renevey, N., Bshary, R. \& van de Waal, E. (2013). Philopatric vervet monkey females are the focus of social attention rather independently of rank. - Behaviour 150: 599-615.

Russello, M.A., Avery, M.L. \& Wright, T.F. (2008). Genetic evidence links invasive monk parakeet populations in the United States to the international pet trade. - BMC Evol. Biol. 8: 217.

Schuett, W. \& Dall, S.R. (2009). Sex differences, social context and personality in zebra finches, Taeniopygia guttata. - Anim. Behav. 77: 1041-1050.

Schuett, W., Tregenza, T. \& Dall, S.R. (2010). Sexual selection and animal personality. Biol. Rev. 85: 217-246.

Schuett, W., Dall, S.R. \& Royle, N.J. (2011). Pairs of zebra finches with similar 'personalities' make better parents. — Anim. Behav. 81: 609-618.

Sewall, K.B. (2015). Social complexity as a driver of communication and cognition. - Integr. Comp. Biol. 55: 384-395.

Short, K.H. \& Petren, K. (2008). Boldness underlies foraging success of invasive Lepidodactylus lugubris geckos in the human landscape. - Anim. Behav. 76: 429-437.

Sieving, K.E., Contreras, T.A. \& Maute, K.L. (2004). Heterospecific facilitation of forestboundary crossing by mobbing understory birds in north-central Florida. - Auk 121: 738-751.

Soma, M. \& Hasegawa, T. (2004). The effect of social facilitation and social dominance on foraging success of budgerigars in an unfamiliar environment. - Behaviour 141: 11211134.

South, J.M. \& Pruett-Jones, S. (2000). Patterns of flock size, diet, and vigilance of naturalized monk parakeets in Hyde Park, Chicago. — Condor 102: 848-854.

Stevens, J. (1992). Applied multivariate statistics for the social sciences. - Lawrence Erlbaum Associates, Hillsdale, NJ.

Stowe, M., Bugnyar, T., Loretto, M.C., Schloegl, C., Range, F. \& Kotrschal, K. (2006). Novel object exploration in ravens (Corvus corax): effects of social relationships. - Behav. Process. 73: 68-75.

Strubbe, D. \& Matthysen, E. (2009). Establishment success of invasive ring-necked and monk parakeets in Europe. - J. Biogeogr. 36: 2264-2278. 
Tallent, B.R., Law, L.M., Rowe, R.K. \& Lifshitz, J. (2018). Partial cage division significantly reduces aggressive behavior in male laboratory mice. — Lab. Anim. 52: 384-393.

Thorpe, R.S. (1988). Multiple group principal component analysis and population differentiation. - J. Zool. 216: 37-40.

Toscano, B.J., Gownaris, N.J., Heerhartz, S.M. \& Monaco, C.J. (2016). Personality, foraging behavior and specialization: integrating behavioral and food web ecology at the individual level. - Oecologia 182: 55-69.

Traisnel, G. \& Pichegru, L. (2018). Does it always pay to defend one's nest? A case study in African penguin. - Ethology 124: 74-83.

Vale, G.L., Davis, S.J., van de Waal, E., Schapiro, S.J., Lambeth, S.P. \& Whiten, A. (2017). Lack of conformity to new local dietary preferences in migrating captive chimpanzees. Anim. Behav. 124: 135-144.

van de Waal, E., Renevey, N., Favre, C.M. \& Bshary, R. (2010). Selective attention to philopatric models causes directed social learning in wild vervet monkeys. - Proc. Roy. Soc. Lond. B: Biol. Sci. 277: 2105-2111.

van de Waal, E., Borgeaud, C. \& Whiten, A. (2013). Potent social learning and conformity shape a wild primate's foraging decisions. - Science 340: 483-485.

van den Brink, V., Dolivo, V., Falourd, X., Dreiss, A.N. \& Roulin, A. (2012). Melanic colordependent antipredator behavioral strategies in barn owl nestlings. - Behav. Ecol. 23: 473-480.

van Horik, J.O., Langley, E.J., Whiteside, M.A. \& Madden, J.R. (2017). Differential participation in cognitive tests is driven by personality, sex, body condition and experience. Behav. Process. 134: 22-30.

van Oers, K., Klunder, M. \& Drent, P.J. (2005). Context dependence of personalities: risktaking behavior in a social and a nonsocial situation. - Behav. Ecol. 16: 716-723.

Vander Wal, E., Festa-Bianchet, M., Réale, D., Coltman, D.W. \& Pelletier, F. (2015). Sexbased differences in the adaptive value of social behavior contrasted against morphology and environment. — Ecology 96: 631-641.

Webster, M.M. \& Ward, A.J.W. (2011). Personality and social context. - Biol. Rev. 86: 759-773.

Webster, M.M. \& Laland, K.N. (2012). Social information, conformity and the opportunity costs paid by foraging fish. - Behav. Ecol. Sociobiol. 6: 797-809.

White, C.M., Marks, J.S. \& Kirwan, G.M. (2018). Sharp-shinned hawk (Accipiter striatus). - In: Handbook of the birds of the world alive (del Hoyo, J., Elliott, A., Sargatal, J., Christie, D.A. \& de Juana, E., eds). Lynx Edicions, Barcelona, available online at https:// www.hbw.com/node/53079 (accessed 28 July 2018).

Whiten, A., Horner, V. \& De Waal, F.B.M. (2005). Conformity to cultural norms of tool use in chimpanzees. - Nature 437: 737.

Wickham, H., Chang, W. \& Wickham, M.H. (2013). Package 'ggplot2'. — CRAN, Comprehensive R Archive Network for the R programming language.

Wilson, A.D.M. \& Godin, J.-G.J. (2010). Boldness and intermittent locomotion in the bluegill sunfish, Lepomis macrochirus. - Behav. Ecol. 21: 57-62. 
Wilson, D.S., Clark, A.B., Coleman, K. \& Dearstyne, T. (1994). Shyness and boldness in humans and other animals. - Trends Ecol. Evol. 9: 442-446.

Zou, F., Jones, H., Jiang, D., Lee, T.M., Martínez, A., Sieving, K., Zhang, M., Zhang, Q. \& Goodale, E. (2018). The conservation implications of mixed-species flocking in terrestrial birds, a globally-distributed species interaction network. — Biol. Cons. 224: 267-276.

\section{Appendix}

Table A1.

Sex differences in behavioural metrics captured in the social treatment.

\begin{tabular}{llc}
\hline Behavioural measures & $W$ & $p$ \\
\hline Latency to enter the novel environment & 477 & 0.72 \\
Latency to consume food when novel object is present & 454.5 & 0.51 \\
Proportion of time spent feeding & 607.5 & 0.17 \\
Pecking frequency when novel object is present & 576 & 0.34 \\
Total number of feeding approaches & 472 & 0.67 \\
Total number of vocalizations when exposed to a predator & 526 & 0.77 \\
Total number of flights when exposed to a predator & 446.5 & 0.44 \\
\hline
\end{tabular}

Wilcoxon signed-rank test of the effect of sex on the behavioural metrics measured during assays conducted in the presence of conspecifics. Bonferroni corrected significance level is set to 0.01 . 